\title{
Diffusion in FCC Co-rich Co-Al-W Alloys at 900 and $1000{ }^{\circ} \mathrm{C}$
}

\author{
K.-W. Moon, C.E. Campbell, M.E. Williams, and W.J. Boettinger
}

(Submitted April 20, 2016; in revised form July 4, 2016; published online July 27, 2016)

\begin{abstract}
Diffusion couple experiments between various Co-rich face centered cubic (FCC) alloys in the Co-W-Al ternary system have been conducted at 900 and $1000{ }^{\circ} \mathrm{C}$. Diffusion coefficients have been extracted for the Co-W binary and for ternary alloys at compositions where the diffusion paths cross. In addition, a least squares method has been utilized to optimize diffusion mobility parameters using DICTRA simulations to best fit the experimental concentration versus distance curves. Predictions of the diffusion matrix using the refined mobility database are in good agreement with the values obtained at the diffusion path crossing points.
\end{abstract}

Keywords Co-W-Al ternary system, DICTRA, diffusivity, experiment data error reduction, mobility database optimization, Sauer-Freise method

\section{Introduction}

In 2006 Sato et al. ${ }^{[1]}$ identified the existence of a $\gamma / \gamma^{\prime}$ microstructure in the Co-Al-W system, similar to that in the $\mathrm{Ni}-\mathrm{Al}$ system that is used as the basis for many high temperature superalloys. The presence of the $\gamma / \gamma^{\prime}$ microstructure in Co-based alloys has spurred several research efforts ${ }^{[2-5]}$ to develop a new class of Co-based high temperature superalloys that have the potential to increase turbine engine operating temperature by $50{ }^{\circ} \mathrm{C}$. Despite these efforts, only a limited number of research efforts have been focused on developing the thermodynamics $^{[6-8]}$ and diffusion descriptions. ${ }^{[9]}$ Much of the current materials design work for these new Co-based superalloys is based on previous thermodynamic and diffusion assessments for the Ni-base superalloys and the cemented carbide systems.

Initial research on the stability of $\gamma^{\prime}$ in the Co-Al-W system at $900{ }^{\circ} \mathrm{C}$ were inconclusive: Sato et al. initially reported the $\gamma^{\prime}$ phase to be stable while work by Kobayashi and Tsukamoto ${ }^{[10,11]}$ indicated the $\gamma^{\prime}$ was not stable. To resolve this inconsistency, Lass et. al. ${ }^{[6]}$ performed long time phase equilibria studies that confirmed that $\gamma^{\prime}$ is not a stable phase at $900{ }^{\circ} \mathrm{C}$ in the Co-Al-W system. However, the metastable $\gamma^{\prime}$ phase dissolves very slowly and remains present even after $4000 \mathrm{~h}$ at $900{ }^{\circ} \mathrm{C}$. Based on these results, diffusion couple studies in the face centered cubic (FCC) phase region of the Co-Al-W system were initiated.

K.-W. Moon, C.E. Campbell, and M.E. Williams, Materials Science and Engineering Division, NIST, Gaithersburg, MD; W.J. Boettinger, Materials Science and Engineering Division, NIST, Gaithersburg, MD and Theiss Research, La Jolla, CA 92037. Contact e-mail: kil-won. moon@nist.gov.

\section{Literature Review}

For the Co-Al, Co-W, Al-W and Co-Al-W systems, several experimental studies and assessments of the diffusion mobility as functions of composition and temperature have been reported in the literature. Peterson and Rothman, ${ }^{[12]}$ Anand and Agarwala ${ }^{[13]}$ and Patvil and Tiwari ${ }^{[14]}$ measured the Co impurity diffusion coefficient in the $\mathrm{Al}$ FCC phase. Green and Swindells, ${ }^{[15]}$ Minamino et al. ${ }^{[16]}$ and Cui et al. ${ }^{[17]}$ have reported interdiffusion data for the Co-Al system in the FCC phase at temperatures from 900 to $1300{ }^{\circ} \mathrm{C}$. Cui et al. ${ }^{[17]}$ combined the available experimental data to develop composition-temperature dependent functions to describe the diffusion mobility in the Co-Al system for the FCC phase, following the methods outlined by Agren and co-workers. ${ }^{[18-20]}$ The Co-W mobility functions in the FCC phase have been recently assessed by both Zhang et al. ${ }^{[21]}$ and Cui et al. ${ }^{[22]}$ Specific Al-W binary diffusion couple studies have not been reported, but both Chang et al., ${ }^{[9]}$ Obata et al. ${ }^{[23]}$ Kobayashi et al. ${ }^{[10]}$ investigated the ternary Co-Al-W system in the FCC phase region in the temperature range from 900 to $1300{ }^{\circ} \mathrm{C}$. Other multicomponent diffusion-couple studies were conducted by G\&mez-Acebo et al. ${ }^{[24]}$ who studied the Al-Co-Cr-Ni-Ti system and by Minamino et al. who studied the Co-Al-Cr$\mathrm{Ni}$ system. ${ }^{[16]}$ In addition the experimental diffusion work on Ni-base superalloys (including Co) prior to 2002 was summarized by Campbell et al. ${ }^{[25]}$ and a database of composition and temperature dependent mobility functions was constructed. Table 1 summarizes the diffusion mobility parameters reported in these previous assessments. ${ }^{[9,21,24,25]}$ The diffusion mobility assessments reported for the Ni-base superalloy systems ${ }^{[25]}$ were used as initial values for the reoptimization of mobility parameters in this work.

\section{Experimental Procedure}

To study the diffusion mobilities in the Co-Al-W system in the single-phase FCC region, diffusion couples were 


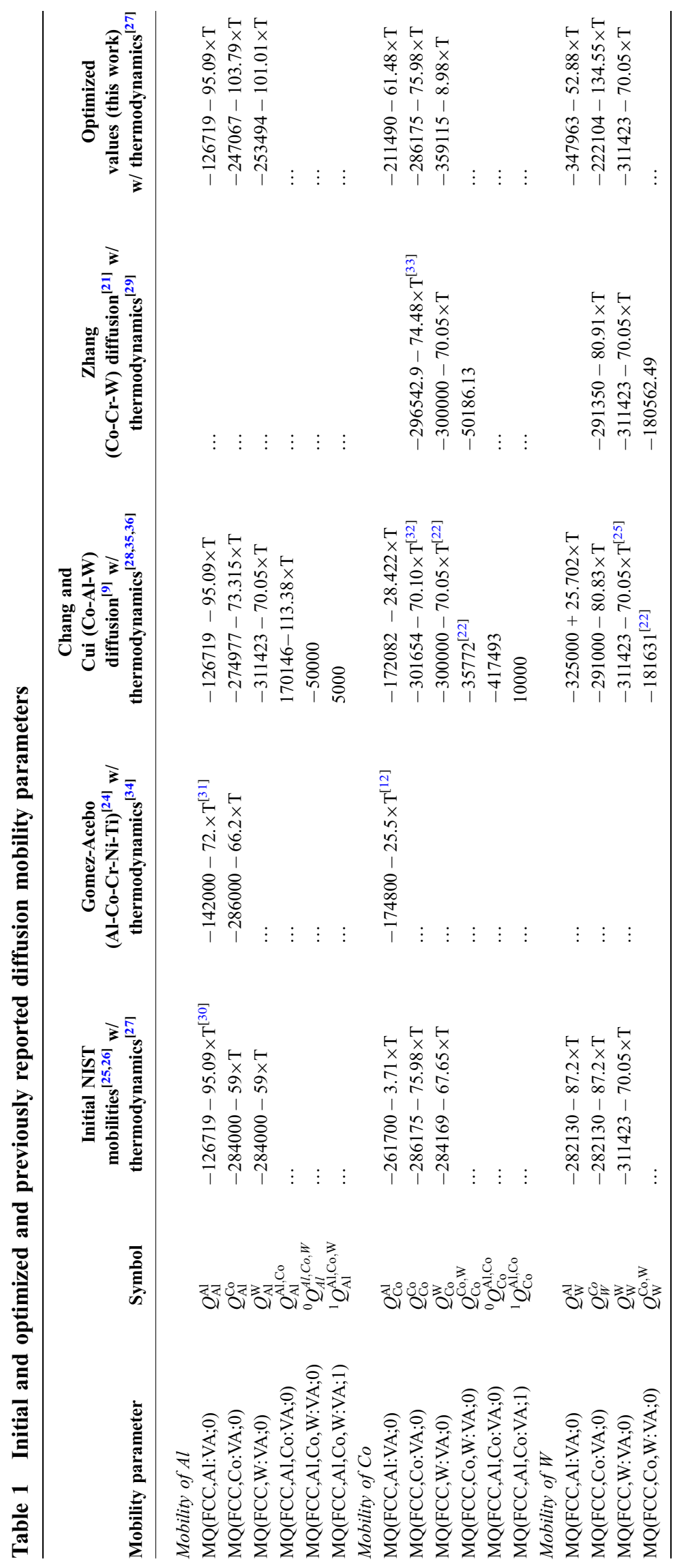


Table 2 End member compositions, homogenization annealing conditions

\begin{tabular}{|c|c|c|c|c|c|c|c|}
\hline \multirow{2}{*}{\multicolumn{2}{|c|}{$\begin{array}{l}\text { Nominal compositions } \\
\text { (mole fractions) }\end{array}$}} & & \multirow{2}{*}{$\begin{array}{c}\text { Homogenization conditions for end } \\
\text { members }\end{array}$} & \multirow[b]{2}{*}{ Shape } & \multicolumn{3}{|c|}{ Measured compositions (mole fraction)* } \\
\hline & & & & & Al & Co & $\mathbf{W}$ \\
\hline \multirow[t]{2}{*}{$\mathbf{a}$} & Co & $\mathbf{a}$ & $1250{ }^{\circ} \mathrm{C}$ for $2 \mathrm{~h}$ & Rod & & $1.0000 \pm 0.0000$ & \\
\hline & & $\mathbf{a}^{\prime}$ & $1320{ }^{\circ} \mathrm{C}$ for $6 \mathrm{~h}$ and $1250{ }^{\circ} \mathrm{C}$ for $60 \mathrm{~h}$ & Slab & & $1.0000 \pm 0.0000$ & \\
\hline \multirow[t]{2}{*}{ c } & Co-0.080 Al-0.040 W & $\mathbf{c}$ & $1250{ }^{\circ} \mathrm{C}$ for $2 \mathrm{~h}$ & Rod & $0.0816 \pm 0.0004$ & $0.8799 \pm 0.0010$ & $0.0385 \pm 0.0006$ \\
\hline & & $\mathbf{c}^{\prime}$ & $1220^{\circ} \mathrm{C}$ for $120 \mathrm{~h}$ & Slab & $0.0808 \pm 0.0030$ & $0.8803 \pm 0.0028$ & $0.0389 \pm 0.0036$ \\
\hline \multirow[t]{2}{*}{ d } & Co- $0.025 \mathrm{~W}$ & d & $1250^{\circ} \mathrm{C}$ for $2 \mathrm{~h}$ & Rod & & $0.9754 \pm 0.0008$ & $0.0246 \pm 0.0008$ \\
\hline & & $\mathbf{d}^{\prime}$ & $1320{ }^{\circ} \mathrm{C}$ for $6 \mathrm{~h}$ and $1250{ }^{\circ} \mathrm{C}$ for $60 \mathrm{~h}$ & Slab & & $0.9748 \pm 0.0022$ & $0.0252 \pm 0.0022$ \\
\hline \multirow[t]{2}{*}{ i } & Co-0.085 Al & $\mathbf{i}$ & $1250{ }^{\circ} \mathrm{C}$ for $2 \mathrm{~h}$ & Rod & $0.0876 \pm 0.0006$ & $0.9124 \pm 0.0006$ & \\
\hline & & $\mathbf{i}^{\prime}$ & $1200{ }^{\circ} \mathrm{C}$ for $43 \mathrm{~h}$ & Slab & $0.0863 \pm 0.0006$ & $0.9137 \pm 0.0006$ & \\
\hline \multirow[t]{2}{*}{$\mathbf{j}$} & Co- $-0.050 \mathrm{~W}$ & $\mathbf{j}$ & $1250^{\circ} \mathrm{C}$ for $2 \mathrm{~h}$ & Rod & & $0.9503 \pm 0.0030$ & $0.0497 \pm 0.0030$ \\
\hline & & $\mathbf{j}^{\prime}$ & $1320{ }^{\circ} \mathrm{C}$ for $6 \mathrm{~h}$ and $1250{ }^{\circ} \mathrm{C}$ for $60 \mathrm{~h}$ & Slab & & $0.9446 \pm 0.0010$ & $0.0534 \pm 0.0010$ \\
\hline
\end{tabular}

The standard error is given by $2 \sigma . *$ Determined by EDS

assembled using end members with the following nominal compositions in mole fraction:

- Co (a) versus Co-0.025 W (d)

- Co (a) versus Co-0.080 Al-0.040 W (c)

- $\mathrm{Co}-0.025 \mathrm{~W}$ (d) versus Co-0.085 Al (i)

- Co-0.085 Al (i) versus Co-0.050 W (j)

- Co-0.025 W (d) versus Co-0.080 Al-0.040W (c).

The bold lower case letters will be used as an alloy designation. These combinations of compositions* yielded several ternary diffusion path crossover compositions (see Fig. 4).

The end member alloys were arc melted from $\mathrm{Co}, \mathrm{Al}$, and W elements, with purities in mass fractions of $99.9 \%$, $99.999 \%$, and $99.97 \%$, respectively. The measured end member alloy compositions and homogenization conditions are summarized in Table 2. As the research progressed, additional ingots were made (designated with primes) and the homogenization treatment altered. The diffusion couple experiments for which the end members were used are listed in the Table 3. The homogenization time and temperatures for the second ingots were increased because of the difficulty of obtaining uniform $\mathrm{W}$ profiles due to residual dendritic micro-segregation resulting from the arc casting. Even after the higher temperature treatment a small amount of micro-segregation remained. For example for the Co- 0.05 $\mathrm{W}$ mole fraction end member, a variation of \pm 0.0011 mole fraction W $(2 \sigma)$ remained on an approximate length scale of $40 \mu \mathrm{m}$.

The treated ingots were cut into rectangular pieces $9 \mathrm{~mm} \times 9 \mathrm{~mm} \times 5 \mathrm{~mm}$ or $11 \mathrm{~mm} \times 11 \mathrm{~mm} \times 10 \mathrm{~mm}$ approximately. Two adjacent faces of the pieces were ground and polished to a finish obtained with $1 \mu \mathrm{m}$ diamond suspension. Columnar stacks of the various alloys up to six pieces were assembled. For the $900{ }^{\circ} \mathrm{C}$ diffusion experiment, stacks were loaded vertically with a $315 \mathrm{~g}$ weight and

*Note all compositions are given in mole fraction, unless otherwise stated.
Table 3 Summary of diffusion experiments

\begin{tabular}{|c|c|c|}
\hline $\begin{array}{l}\text { Temperature } \\
\left({ }^{\circ} \mathrm{C}\right)\end{array}$ & Time (h) & $\begin{array}{c}\text { Detailed } \\
\text { diffusion experiment end members }\end{array}$ \\
\hline \multirow[t]{2}{*}{900} & 477 & $\mathbf{a c}, \mathbf{d i}$, and $\mathbf{i j}$ \\
\hline & 580 & ad (binary) \\
\hline 1000 & 240 & $\mathbf{a}^{\prime} \mathbf{c}^{\prime}, \mathbf{c}^{\prime} \mathbf{d}^{\prime}, \mathbf{d}^{\prime} \mathbf{i}^{\prime}, \mathbf{i}^{\prime} \mathbf{j}^{\prime}$, and $\mathbf{a}^{\prime} \mathbf{d}^{\prime}$ (binary) \\
\hline
\end{tabular}

annealed in a vacuum furnace for either 477 or $580 \mathrm{~h}$ as indicated in Table 3. A Mo-alloy clamp was used for the stack annealed at $1000{ }^{\circ} \mathrm{C}$ for $240 \mathrm{~h}$ in a vacuum ampule.

After the diffusion treatment, the stacks were mounted in epoxy, sectioned parallel to the columnar direction, ground and polished. All diffusion couples were examined by SEM microscopy for quality of the bond regions. The grain size was noted to be larger than $250 \mu \mathrm{m}$ so that grain boundary diffusion could be neglected. Composition profiles were measured using a JEOL JSM-7100 FE-SEM with an Oxford Instruments $\mathrm{X}-\mathrm{Max}^{\mathrm{n}} 80$ silicon drift detector.** The FESEM conditions were $15 \mathrm{keV}$ and $1.0 \mathrm{nA}$. The acquisition times were chosen as $1000 \mathrm{~s}$ for elemental standards and $400 \mathrm{~s}$ for samples. The Co K, W L, and Al K lines were used. The penetration profiles of each diffusion couple were measured along 4-5 parallel lines using the point analysis mode across the diffusion zone with steps of 2 and $5 \mu \mathrm{m}$ for the regions inside and outside of the diffusion zone, respectively. A typical example of the location of the line scans is shown in Fig. 3, where the dark spots from carbon deposits by the e-beam, represent measured positions.

The composition analysis was performed with Oxford Aztec software using elemental standards. The software provided the estimated standard deviation of the composition measurements in mass fraction, which was converted to mole fraction. A typical example of the standard deviation

\footnotetext{
**Commercial names are used for completeness and do not constitute an endorsement from NIST.
} 
for the ac couple $\left(900{ }^{\circ} \mathrm{C}\right)$ couple, gives the following. At the pure $\mathrm{Co}$ end, the measured composition with its standard deviation was $(0.001 \pm 0.0002)$ mole fraction of $\mathrm{Al}$ and $(0.001 \pm 0.0004)$ mole fraction of W. At the alloy end, the measured composition with its standard deviation was $(0.080 \pm 0.0004)$ mole fraction of $\mathrm{Al}$ and $(0.04 \pm 0.0005)$ mole fraction of $\mathrm{W}$.

\section{Data Smoothing}

Data smoothing is required especially due to the composition variation in the $\mathrm{W}$ profiles in the end members and because differentiation of the penetration curves is required. Each data set, composition versus distance, was noise filtered using a discrete Fourier Gauss filter with $1 \mu \mathrm{m}$ full width half maximum (FWHM) approximately and was repeated 5-15 times. Repeating the filtration process using a smaller FWHM showed a better result than a single process using a larger FWHM. The smaller FWHM reduced the scatter but retained the characteristics of the penetration curves. A Fourier series function was used to fit the data in the diffusion zone. This function was truncated at the position where it intersected the constant end member composition values obtained by averaging over a suitable distance range using data outside the diffusion zone. This composite function was then splined.

The Matano interface position was computed using the splined data by the usual method. Then, the distance coordinate of each line scan was shifted so that its Matano position was assigned the value of zero. The $\mathrm{x}$-distance corrected experiment data for the parallel line scans were merged into a single set. This single data set is defined as the merged data. The whole smoothing process was re-applied to this merged data for the noise reduction and a single splined data set was obtained. This final splined data was used to calculate diffusivities and to optimize the CALPHAD mobility database as described later.

\section{Experimental Results}

All diffusion couples consisted of only the FCC phase. The results for 900 and $1000{ }^{\circ} \mathrm{C}$ are given in Fig. 1-5. Fig. 1 shows the $\mathrm{W}$ penetration curves in $\mathrm{W}$ mole fraction versus scaled distance $z / \sqrt{t}$ for the binary Co-W diffusion couples where $t$ is the diffusion time and $z$ is the spatial coordinate. The blue color represents diffusion couples annealed at $900{ }^{\circ} \mathrm{C}$, and the red color represents diffusion couples annealed at $1000{ }^{\circ} \mathrm{C}$. The circles represent the merged data, and the solid lines represent the splined data. Figure 2 shows the $\mathrm{Al}$ and $\mathrm{W}$ penetration curves for the ternary diffusion couples. Figure 3 shows an example of a micrograph of the diffusion zone in the ternary couple (di) after the $1000{ }^{\circ} \mathrm{C}$ treatment. The structure is featureless and clearly single phase. The spots of the microprobe analysis are visible as is a rectangular region where a detailed examination of the bond region was conducted. Figure 4

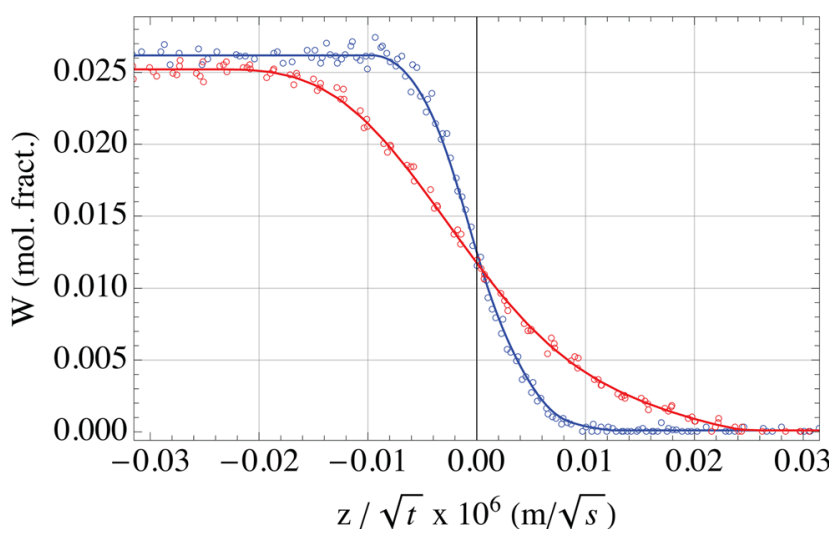

Fig. 1 W concentration vs. scaled distance for Co vs. Co$0.025 \mathrm{~W}$ mole fraction (ad) diffusion couples annealed at $900{ }^{\circ} \mathrm{C}$ for $580 \mathrm{~h}$ (blue) and at $1000{ }^{\circ} \mathrm{C}$ for $240 \mathrm{~h}$ (red). Circles represent the merged data and lines represent the splined curve

shows the diffusion paths, Al composition versus W composition for the ternary couples and Figure 5 shows a magnified view of the central portion of the paths and the location of the intersection compositions to be used for the determination of the ternary interdiffusion matrix as described below.

\section{Analysis Methods}

The variation of molar volume with composition was neglected in this research. The assessment of molar volume of the Co-Al-W FCC alloys ${ }^{[37]}$ gives a variation of molar volume of $2.2 \%$ from pure Co to $\mathrm{Co}-0.08 \mathrm{Al}-0.04 \mathrm{~W}$ (ac). The interdiffusion flux of a component as a function of distance was obtained using the Sauer-Freise formalism applied to interpolation functions obtained from the penetration curves. For the ternary system, the flux $J_{i}$ of each component as a function of position $z$ for constant molar volume is evaluated from

$$
\begin{aligned}
J_{i}(z)= & -\frac{1}{2 t V_{m}} \frac{1}{\left(x_{i}^{R}-x_{i}^{L}\right)} \\
& {\left[\left(x_{i}^{R}-x_{i}(z)\right) \int_{-\infty}^{z}\left(x_{i}(z)-x_{i}^{L}\right) d z\right.} \\
& \left.+\left(x_{i}(z)-x_{i}^{L}\right) \int_{z}^{-\infty}\left(x_{i}^{R}-x_{i}(z)\right) d z\right]
\end{aligned}
$$

and is related to the diffusion coefficients using

$J_{i}(z)=-\frac{1}{V_{m}}\left[\tilde{D}_{i 1}^{3} \frac{\partial x_{1}}{\partial z}+\tilde{D}_{i 2}^{3} \frac{\partial x_{2}}{\partial z}\right]$

where $t$ is the diffusion time, $V_{m}$ is the molar volume, $i$ is element $(i=1,2), x_{i}^{L}$ and $x_{i}^{R}$ are the left $(-\infty)$ and right $(+\infty)$ 

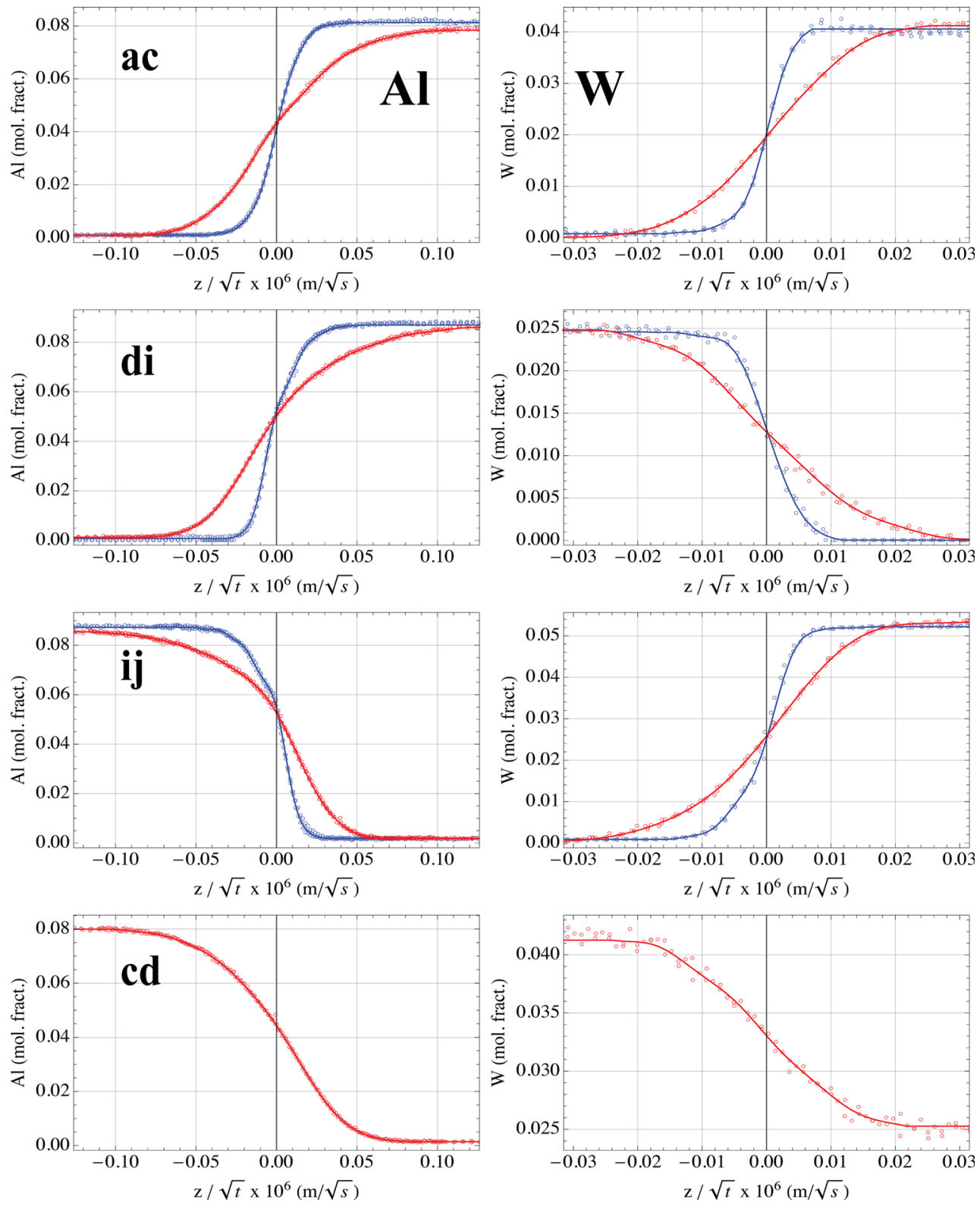

Fig. $2 \mathrm{Al}$ and $\mathrm{W}$ composition vs. scaled distance for four-diffusion couples annealed at $900{ }^{\circ} \mathrm{C}$ for $580 \mathrm{~h}$ (blue) and $1000{ }^{\circ} \mathrm{C}$ for $240 \mathrm{~h}$ (red). Circles represent the merged data and lines represent the splined curve

terminal mole fractions and $\tilde{D}_{i 1}^{3}$ and $\tilde{D}_{i 2}^{3}$ are mole fraction diffusivities. ${ }^{[38]}$ For the binary system, the interdiffusion coefficient $D$ is estimated from

$$
\begin{aligned}
\tilde{D}= & \frac{1}{2 t} \frac{1}{\left(x_{R}-x_{L}\right)} \frac{1}{d x(z) / d z}\left[\left(x_{R}-x(z)\right) \int_{-\infty}^{z}\left(x(z)-x_{L}\right) d z\right. \\
& \left.+\left(x(z)-x_{L}\right) \int_{z}^{-\infty}\left(x_{R}-x(z)\right) d z\right]
\end{aligned}
$$

where $t$ is the diffusion time, and $x_{L}$ and $x_{R}$ are the left $(-\infty)$ and right $(+\infty)$ terminal mole fractions.

The concentration gradients were obtained from the splined data. For the binary couple, the value of the interdiffusion coefficient was obtained at each position by dividing the flux by the negative of the gradient. Hall's method could not be used near the end member compositions due to the scatter in the data.

For the ternary samples, the method of crossing diffusion paths was used to determine the values of the interdiffusion coefficient $(\tilde{D})$ matrix at the intersection composition with Co considered as the dependent component. The interdif- 


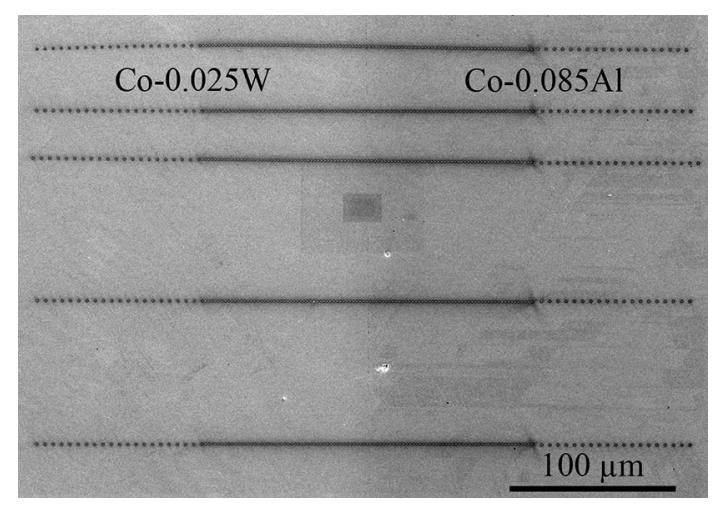

Fig. 3 A typical microstructure of Co- $0.025 \mathrm{~W}$ vs. Co- $0.085 \mathrm{Al}$ (di) diffusion couple boundary annealed at $1000{ }^{\circ} \mathrm{C}$ for $240 \mathrm{~h}$. Dark spots, carbon contaminants by e-beam, represent measured positions. Penetration profiles were measured five times by a line scan using a point analysis mode across the diffusion zone by steps of 2 and $5 \mu \mathrm{m}$

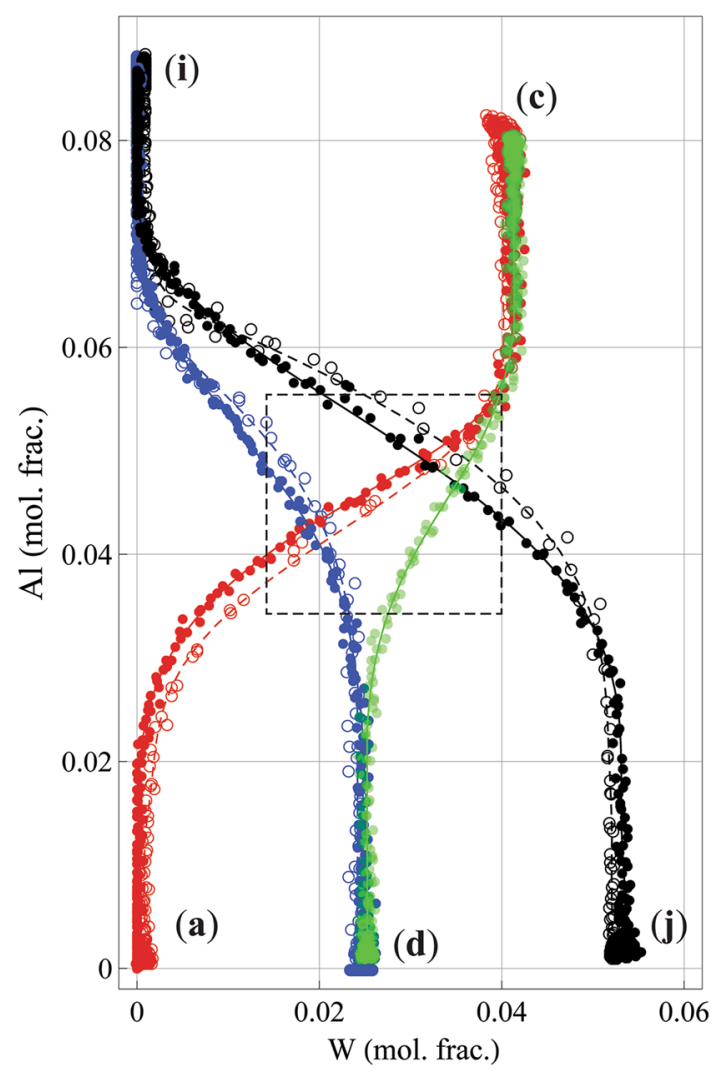

Fig. 4 Diffusion paths of Co vs. Co-0.080Al-0.040W (ac), Co$0.025 \mathrm{~W}$ vs. Co-0.085Al (di), Co-0.050W vs. Co-0.085Al (ij), and $\mathrm{Co}-0.025 \mathrm{~W}$ vs. Co-0.080Al-0.040W (dc) diffusion couples annealed at $900{ }^{\circ} \mathrm{C}$ for $477 \mathrm{~h}$ (open circle) and at $1000{ }^{\circ} \mathrm{C}$ for $240 \mathrm{~h}$ (filled circle). Circles represent the merged data and lines represent the splined curve. Only the diffusion path annealed at $1000{ }^{\circ} \mathrm{C}$ for $240 \mathrm{~h}$ of the cd couple is presented in this figure. The area of dashed square is enlarged in Fig. 5

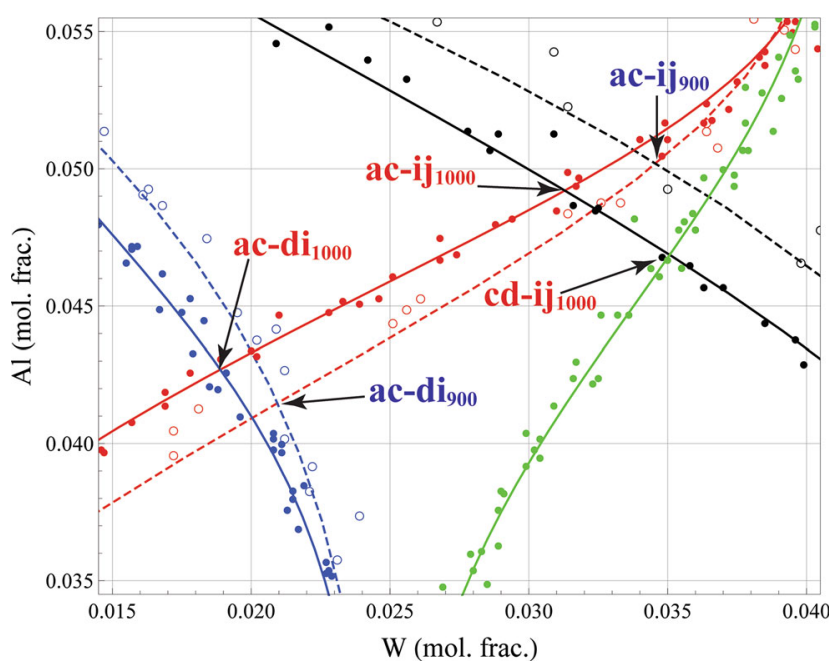

Fig. 5 Enlarged figure of rectangular area in Fig. 4 showing crossover positions of the various diffusion paths at the two annealing temperatures. Intersection points are labeled according the couples and temperatures. Circles represent the merged data and lines represent the splined curve

fusion fluxes of $\mathrm{Al}$ and $\mathrm{W}$ for the two crossing paths were calculated as a function of spatial position using Eq 1. The positions corresponding to the compositional intersection of the paths was obtained and the fluxes evaluated there. The four concentration gradients of $\mathrm{Al}$ and $\mathrm{W}$ at the two intersection points were determined. A system of two pairs of two linear equations were solved for the four D values, $\tilde{D}_{\mathrm{AIAI}}^{\mathrm{Co}}, \tilde{D}_{\mathrm{AIW}}^{\mathrm{Co}}, \tilde{D}_{\mathrm{WAI}}^{\mathrm{Co}}$, and $\tilde{D}_{\mathrm{WW}}^{\mathrm{Co}}$. Mathematica scripts were employed for these methods.

A CALPHAD-approach as outlined by Ågren and coworkers $^{[18,19,39]}$ was used to model the composition and temperature dependent atomic diffusion mobilities in the substitutional FCC solid solution. Using this approach, the chemical diffusivity in the volume-fixed frame of reference is defined as:

$D_{k j}=\sum_{i=1}^{n}\left(\delta_{i k}-x_{k}\right) x_{i} M_{i} \frac{\partial \mu_{i}}{\partial x_{j}} V_{m}$

where $\delta_{i k}=1$ when $i=k$ and $\delta_{i k}=0$ when $i \neq k, \mu_{i}$ is the chemical potential of element $i$ and $x_{i}$ is the mole fraction of element $i$, and $M_{i}$ is the atomic mobility. The atomic mobility depends on composition and temperature of is

$M_{i}=M_{i}^{0}\left[\exp \left(\frac{-\Delta Q_{i}}{R T}\right)\right] \frac{1}{R T}$

where $R$ is the gas constant, $T$ is temperature, $M_{i}^{0}$ is a frequency factor which includes the atomic jump distance and frequency, and $\Delta Q_{i}$ is an activation energy, which is temperature and composition dependent. For a disordered solid solution phase, the composition dependence of the diffusion mobility is represented using Redlich-Kister ${ }^{[40]}$ polynomials for binary terms and a power series expansion for ternary terms. 


$$
\begin{aligned}
\Delta Q_{i}= & \sum_{p=1}^{n} x_{p} Q_{i}^{p}+\sum_{p}^{n} \sum_{q>p}^{n} x_{p} x_{q}\left[\sum_{r=0}^{m}{ }^{r} A_{i}^{p q}\left(x_{p}-x_{q}\right)^{r}\right] \\
& +\sum_{p} \sum_{q>p} \sum_{v>q} x_{p} x_{q} x_{v}\left[v_{p q v}^{s}{ }^{s} B_{i}^{p q v}\right]
\end{aligned}
$$

where $v_{p q v}^{s}=x_{s}+\left(1-x_{p}-x_{q}-x_{v}\right) / 3$ with $s \in(p, q, v)$, where $Q_{i}^{P}$ is the self-activation energy for component $i$ in a given phase and ${ }^{r} A_{i}^{p q}$ and ${ }^{s} B_{i}^{p q v}$ are binary and ternary interaction parameters, respectively. It should be noted in this work no ternary interaction parameters were considered. The composition dependence of the frequency factor can be represented in the form of Eq 6; however, it is assumed that $M_{i}^{0}$ is exponentially dependent on composition ${ }^{[41]}$ and is included in the activation energy term ${ }^{[20,25]}$

Initial estimates for the mobilities terms $\left(Q_{i}^{P}\right.$ and $\left.{ }^{r} A_{i}^{p q}\right)$ were taken from the NIST Ni mobility database ${ }^{[25,26]}$ given in column 3 of Table 1 . The self-diffusion mobility parameters for $\mathrm{Co}, \mathrm{Al}$ and $\mathrm{W}\left(Q_{\mathrm{Al}}^{\mathrm{Al}}, Q_{\mathrm{Co}}^{\mathrm{Co}}\right.$ and $\left.Q_{\mathrm{W}}^{\mathrm{W}}\right)$ were held constant as these values have been previously established. Using the experimental the ternary $\mathbf{a c}, \mathbf{d i}$, and $\mathbf{i j}$ and binary ad diffusion couple results and the Co-Al binary diffusion data from Cui et al., ${ }^{[17]}$ the initial diffusion mobility parameters were optimized comparing the experimental and calculated diffusion composition profiles. The diffusion simulations were performed using the DICTRA ${ }^{[42]}$ finite-difference code in conjunction with the thermodynamic database by Kattner. ${ }^{[27]}$ All of the simulations used a double geometric grid with 200 points and exponents of 0.98 and 1.02 for the lower and upper parts of geometrical series, respectively. The simulated region was $400 \mu \mathrm{m}$ in length.

Initially the diffusion mobility parameters were optimized by simultaneously comparing nine calculated penetration curves at $900{ }^{\circ} \mathrm{C}$ (one curve for each of the three elements of three diffusion couples) to the experimental penetration curves. It should be noted that this optimization does not include any temperature dependence. A sum of square error matrix was constructed, and selected ternary mobility parameters were varied to minimize the matrix. Best results were obtained with optimizations done one mobility parameter at a time and then repeated sequentially with the other parameters until a reasonable fit was found. After this procedure, a minimization was employed simultaneously varying all of the mobilities to determine the global optimum parameters. The same process was repeated to determine optimized mobilities for the $1000{ }^{\circ} \mathrm{C}$ diffusion experiments. The resulting sets of diffusion mobility parameters from the 900 and $1000{ }^{\circ} \mathrm{C}$ optimizations were combined assuming linear temperature dependence.

The optimized values of the diffusion mobility parameters are given in Table 1. The current optimization includes only the revisions to the terms that represent impurity diffusion in the pure elements and no binary interaction terms. The changes to the pure element terms are generally within $20 \%$ of the original value. The largest changes were to the mobility of $\mathrm{Al}$ and $\mathrm{W}$ in a pure Co matrix. Previous assessments by Cui et al. ${ }^{[8]}$ and Zhang et al. ${ }^{[21]}$ included binary interactions parameters. The current work determined that these binary interaction parameters were not needed to obtain a fit to the data within the experimental error. The dependence of the optimized mobility parameters on the thermodynamic databases was also evaluated. The chemical diffusion (interdiffusion) coefficients calculated using $\mathrm{Ni}$ thermodynamic database by Thermotech ${ }^{[43]}$ were equivalent to those calculated using the thermodynamics from Ref 27 .

\section{Results and Discussion}

\subsection{Binary Diffusion Coefficients for Co-W}

Figure 6 shows the value of the interdiffusion coefficient versus composition obtained from the Co versus Co$0.025 \mathrm{~W}$ diffusion couple at 900 and $1000{ }^{\circ} \mathrm{C}$ using the Sauer-Freise method. The error bars represent the maximum and minimum diffusion coefficients determined from interpolation of four-measured penetration curves at the $\mathrm{W}$ compositions. We note a decreasing trend with increasing $\mathrm{W}$ content $x_{\mathrm{W}}$, given by the equation, $\tilde{D}\left(\mathrm{~m}^{2} / s\right)=1.11 \times$ $10^{-17}-1.88 \times 10^{-16} x_{\mathrm{W}}$ for $900{ }^{\circ} \mathrm{C}$ and $\tilde{D}\left(\mathrm{~m}^{2} / \mathrm{s}\right)=$ $7.05 \times 10^{-17}-1.80 \times 10^{-15} x_{\mathrm{W}}$ for $1000{ }^{\circ} \mathrm{C}$. The decreasing trend of the diffusion coefficient with $\mathrm{W}$ content is consistent with the data of Cui et al. ${ }^{[22]}$ obtained between 1000 and $1300{ }^{\circ} \mathrm{C}$. An Arrhenius fit of their data at pure Co (the $\mathrm{W}$ impurity diffusion in pure Co) yields $D_{0}=5.85 \times 10^{-5} \mathrm{~m}^{2} / \mathrm{s}$ and $Q=291.8 \mathrm{~kJ} / \mathrm{mol} \cdot \mathrm{K}$ giving a value of $7 \times 10^{-18} \mathrm{~m}^{2} / \mathrm{s}$ at $900{ }^{\circ} \mathrm{C}$ and $6 \times 10^{-17} \mathrm{~m}^{2} / \mathrm{s}$ at $1000{ }^{\circ} \mathrm{C}$. The present work extrapolated to pure Co gives values of $1.11 \times 10^{-17} \mathrm{~m}^{2} / \mathrm{s}$ at $900{ }^{\circ} \mathrm{C}$ and $7.05 \times 10^{-17} \mathrm{~m}^{2} / \mathrm{s}$ at $1000{ }^{\circ} \mathrm{C}$.

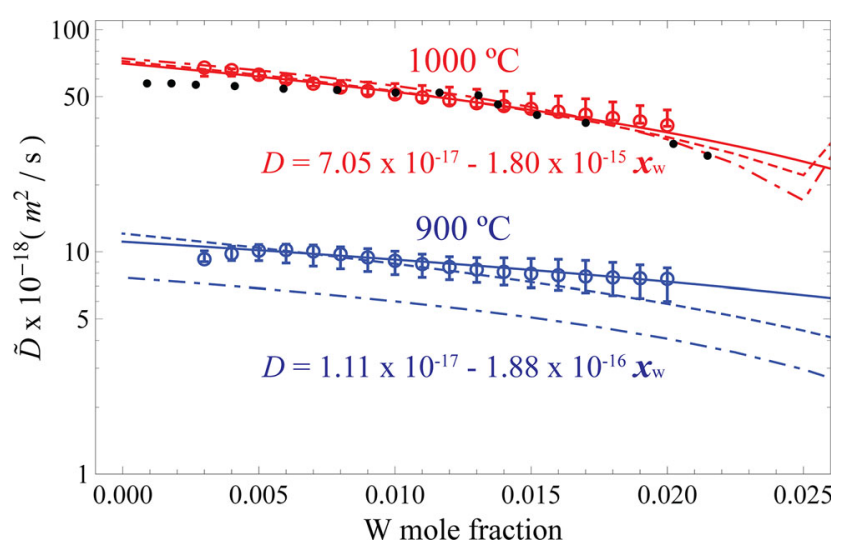

Fig. 6 Interdiffusion coefficients vs. W composition at $1000{ }^{\circ} \mathrm{C}$ (red) and $900{ }^{\circ} \mathrm{C}$ (blue) using the Sauer-Freise method (open circle). Dot-dashed lines represent the interdiffusion coefficients calculated by DICTRA using initial mobility parameters and the dashed lines represent interdiffusion coefficients using optimized mobility parameters. The solid lines are the linear fits of the Sauer-Freise calculated interdiffusion coefficients. Solid black symbols are from data of Cui et al. ${ }^{[22]}$ Note that interdiffusion coefficients for $1000{ }^{\circ} \mathrm{C}$ calculated by DICTRA using initial and optimized parameters are overlapped 
Table 4 Diffusion coefficients measured using intersection method shown (A) and calculated using DICTRA - Poly 3 with optimized parameters (B) and initial parameters (C)

\begin{tabular}{|c|c|c|c|c|c|c|c|}
\hline & \multirow{2}{*}{$\begin{array}{l}\text { Considered } \\
\text { diffusion } \\
\text { paths using } \\
\text { merged data }\end{array}$} & \multicolumn{2}{|c|}{$\begin{array}{c}\text { Experimental crossing } \\
\text { composition }\end{array}$} & \multicolumn{4}{|c|}{ Diffusion coefficients $\left(\mathrm{m}^{2} / \mathrm{s}\right)$ with selected error estimates } \\
\hline & & $x_{\mathrm{Al}}$ & $x_{\mathbf{W}}$ & $\tilde{D}_{\text {AIAI }}^{\text {Co }}$ & $\tilde{\boldsymbol{D}}_{\text {AlW }}^{\mathrm{Co}}$ & $\tilde{D}_{\mathbf{W A I}}^{\mathrm{Co}}$ & $\tilde{D}_{\mathbf{W W}}^{\mathrm{Co}}$ \\
\hline \multicolumn{8}{|c|}{ Determined from crossing paths- $A$} \\
\hline \multirow{5}{*}{$\begin{array}{l}\text { Diffusion at } 900{ }^{\circ} \mathrm{C} \\
\text { for } 477 \mathrm{~h} \\
\text { Diffusion at } 1000^{\circ} \mathrm{C} \\
\text { for } 240 \mathrm{~h}\end{array}$} & ac-di & $0.0416 \pm 0.0005$ & $0.0209 \pm 0.0008$ & $3.38 \pm 0.57 \mathrm{E}-16$ & $0.90 \pm 3.49 \mathrm{E}-17$ & $-6.12 \pm 2.79 \mathrm{E}-18$ & $3.17 \pm 0.33 \mathrm{E}-17$ \\
\hline & ac-ij & $0.0501 \pm 0.0003$ & $0.0339 \pm 0.0005$ & $3.73 \pm 0.37 \mathrm{E}-16$ & $1.13 \pm 2.95 \mathrm{E}-17$ & $-6.97 \pm 4.55 \mathrm{E}-18$ & $3.16 \pm 0.33 \mathrm{E}-17$ \\
\hline & ac-di & $0.0428 \pm 0.0001$ & $0.0189 \pm 0.0002$ & $6.13 \pm 0.27 \mathrm{E}-16$ & $3.69 \pm 1.67 \mathrm{E}-17$ & $-2.11 \pm 2.33 \mathrm{E}-18$ & $5.63 \pm 0.18 \mathrm{E}-17$ \\
\hline & ac-ij & $0.0493 \pm 0.0004$ & $0.0314 \pm 0.0006$ & $6.15 \pm 0.37 \mathrm{E}-16$ & $10.20 \pm 2.03 \mathrm{E}-17$ & $-6.96 \pm 9.20 \mathrm{E}-18$ & $5.50 \pm 0.51 \mathrm{E}-17$ \\
\hline & cd-ij & $0.0470 \pm 0.0004$ & $0.0350 \pm 0.0003$ & $5.81 \pm 0.24 \mathrm{E}-16$ & $10.55 \pm 2.78 \mathrm{E}-17$ & $-0.47 \pm 3.84 \mathrm{E}-18$ & $5.62 \pm 0.34 \mathrm{E}-17$ \\
\hline \multicolumn{8}{|c|}{ Calculated using optimized mobility- $B$} \\
\hline \multirow{5}{*}{$\begin{array}{l}\text { Diffusion at } 900{ }^{\circ} \mathrm{C} \\
\text { for } 477 \mathrm{~h} \\
\text { Diffusion at } 1000{ }^{\circ} \mathrm{C} \\
\text { for } 240 \mathrm{~h}\end{array}$} & ac-di & 0.0416 & 0.0209 & $8.11 \mathrm{E}-17$ & $-1.54 \mathrm{E}-18$ & $-1.27 \mathrm{E}-18$ & $8.21 \mathrm{E}-18$ \\
\hline & ac-ij & 0.0501 & 0.0339 & $1.07 \mathrm{E}-16$ & $1.50 \mathrm{E}-17$ & $-9.23 \mathrm{E}-19$ & $8.65 \mathrm{E}-18$ \\
\hline & ac-di & 0.0428 & 0.0189 & $6.34 \mathrm{E}-16$ & $7.77 \mathrm{E}-17$ & $-5.52 \mathrm{E}-19$ & $6.35 \mathrm{E}-17$ \\
\hline & ac-ij & 0.0493 & 0.0314 & $7.54 \mathrm{E}-16$ & $1.49 \mathrm{E}-16$ & $2.29 \mathrm{E}-18$ & $6.71 \mathrm{E}-17$ \\
\hline & cd-ij & 0.0470 & 0.0350 & $7.23 \mathrm{E}-16$ & $1.42 \mathrm{E}-16$ & $3.80 \mathrm{E}-18$ & $6.82 \mathrm{E}-17$ \\
\hline \multicolumn{8}{|c|}{ Calculated from initial mobility- $C$} \\
\hline \multirow{5}{*}{$\begin{array}{l}\text { Diffusion at } 900{ }^{\circ} \mathrm{C} \\
\text { for } 477 \mathrm{~h} \\
\text { Diffusion at } 1000{ }^{\circ} \mathrm{C} \\
\text { for } 240 \mathrm{~h}\end{array}$} & ac-di & 0.0416 & 0.0209 & $3.39 \mathrm{E}-16$ & $8.14 \mathrm{E}-18$ & $-6.74 \mathrm{E}-18$ & $6.30 \mathrm{E}-18$ \\
\hline & ac-ij & 0.0501 & 0.0339 & $4.42 \mathrm{E}-16$ & $5.93 \mathrm{E}-17$ & $-1.30 \mathrm{E}-17$ & $5.22 \mathrm{E}-18$ \\
\hline & ac-di & 0.0428 & 0.0189 & $3.48 \mathrm{E}-15$ & $3.88 \mathrm{E}-16$ & $-5.52 \mathrm{E}-17$ & $6.52 \mathrm{E}-17$ \\
\hline & ac-ij & 0.0493 & 0.0314 & $4.09 \mathrm{E}-15$ & $7.58 \mathrm{E}-16$ & $1.04 \mathrm{E}-16$ & $5.67 \mathrm{E}-17$ \\
\hline & ac-ij & 0.0470 & 0.0350 & $3.94 \mathrm{E}-15$ & $7.29 \mathrm{E}-16$ & $-1.11 \mathrm{E}-16$ & $5.61 \mathrm{E}-17$ \\
\hline
\end{tabular}

Errors of D's are discussed in text. The standard error is given by $2 \sigma$

\subsection{Ternary Diffusion Coefficients for Co-Al-W from Crossing Paths}

Table 4 gives the values of the four diffusion coefficients determined at the three crossing compositions for diffusion couples ac-ij and $\mathbf{a c}-\mathbf{d i}$ at $900{ }^{\circ} \mathrm{C}$ and $\mathbf{~ a c - i j , ~ a c - d i ~}$ and cd-ij $1000{ }^{\circ} \mathrm{C}$. Also listed are the values of the $D$ matrix at the crossing composition obtained from DICTRA using the initial and optimized mobility parameters. The procedure to obtain the optimized mobilities is described below.

An estimate of the experimental standard error $(2 \sigma)$ for the values of $D$ extracted from the crossing points is given in Table 4. This estimate was determined by employing the intersection method using the individual (non-merged) experimental data and also data smoothed by the method explained in section 3. While the values of the diagonal coefficients are determined with good confidence, the values of the off-diagonal coefficients are less certain. Indeed, for the value of $\tilde{D}_{\mathrm{AlW}}^{\mathrm{Co}}$, one cannot be certain of the sign.

\subsection{Ternary Mobility Parameters for Co-Al-W}

Figure 7 compares the experimental penetration curves to the calculated penetration curves using the initial and optimized mobility databases for the binary diffusion couples, and Fig. 8 and 9 shows the same information for the ternary diffusion couples. The fits to the experimental penetration curves using the optimized mobility parameters are much improved.

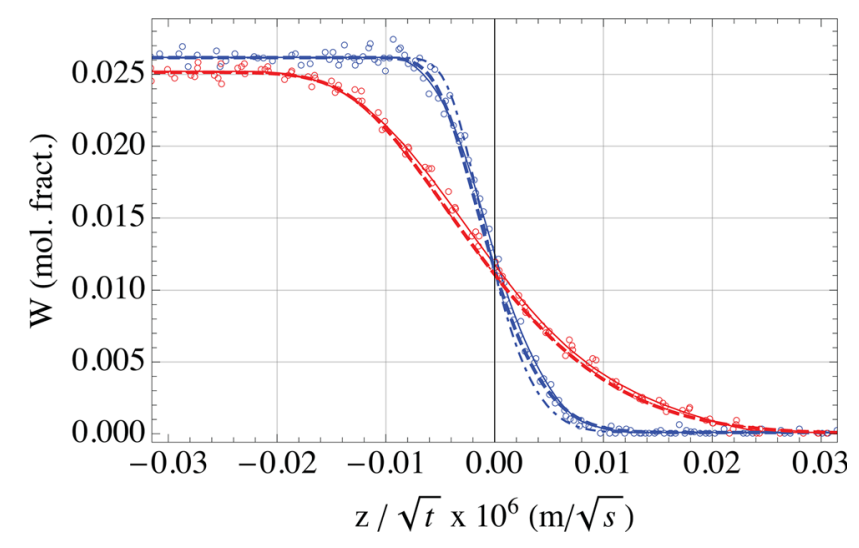

Fig. 7 Comparison between experiment data and calculated data from DICTRA for Co vs. Co-0.025W (ad) diffusion couples at $900{ }^{\circ} \mathrm{C}$ (blue) and $1000{ }^{\circ} \mathrm{C}$ (red). Circles represent the merged data, lines represent the splined curves, dot-dashed lines represent calculated penetration curves using initial parameters of mobility, and dashed lines represent penetration curves using optimized parameters of mobility

The calculated $D$ values at the crossing compositions using the optimized mobility parameters are given in Table 4. The calculated values are in the correct ranges but lie outside of the estimated standard errors for the experimentally determined diffusion coefficients. The diagonal terms of the diffusion matrix agree within $80 \%$ at $900{ }^{\circ} \mathrm{C}$ and $25 \%$ at $1000{ }^{\circ} \mathrm{C}$. The off-diagonal terms have 

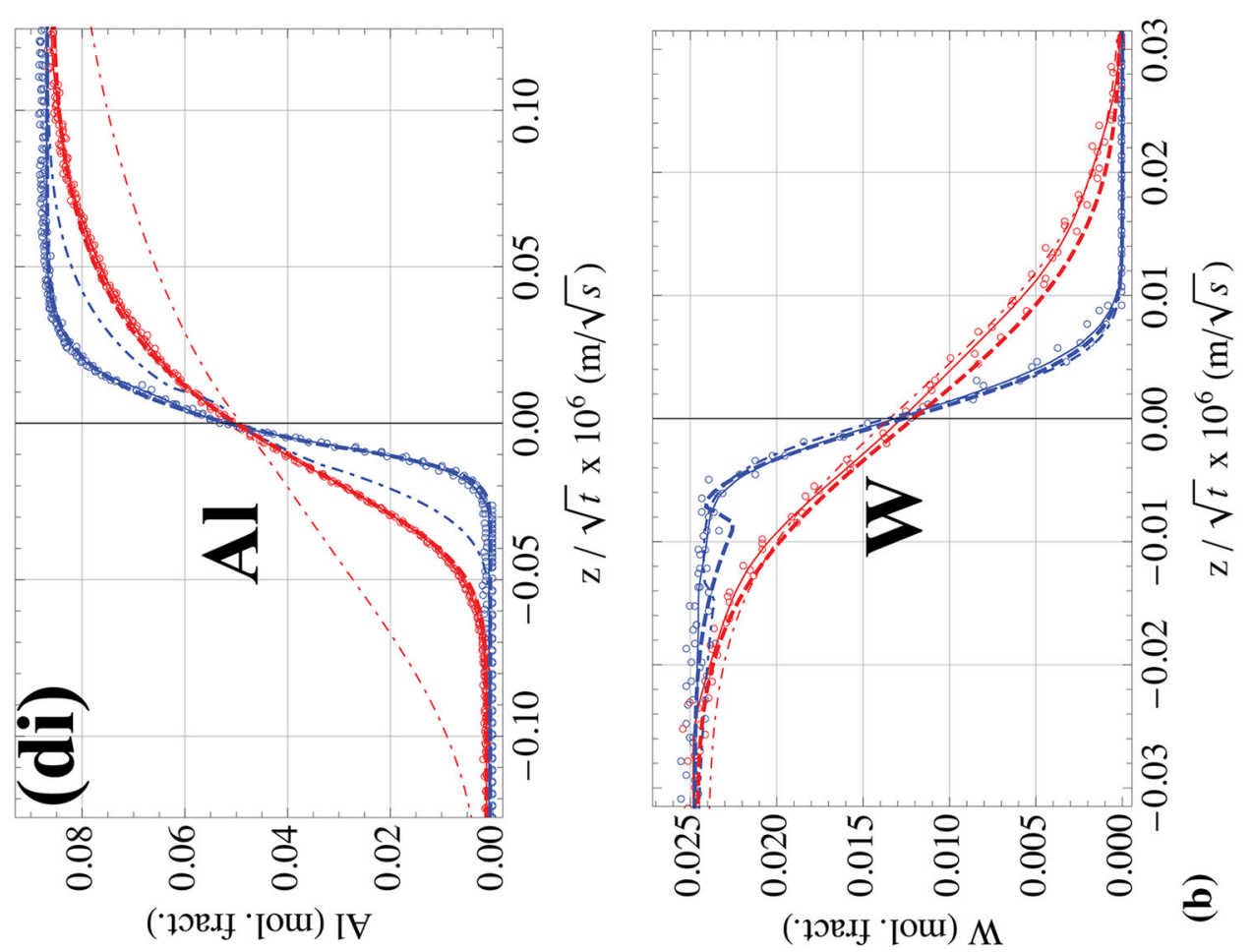

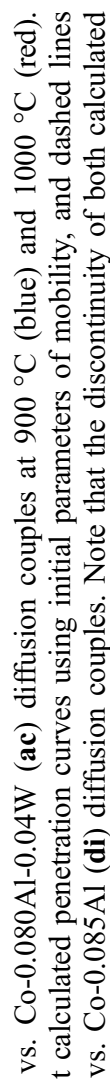

○芽交

훈 훈

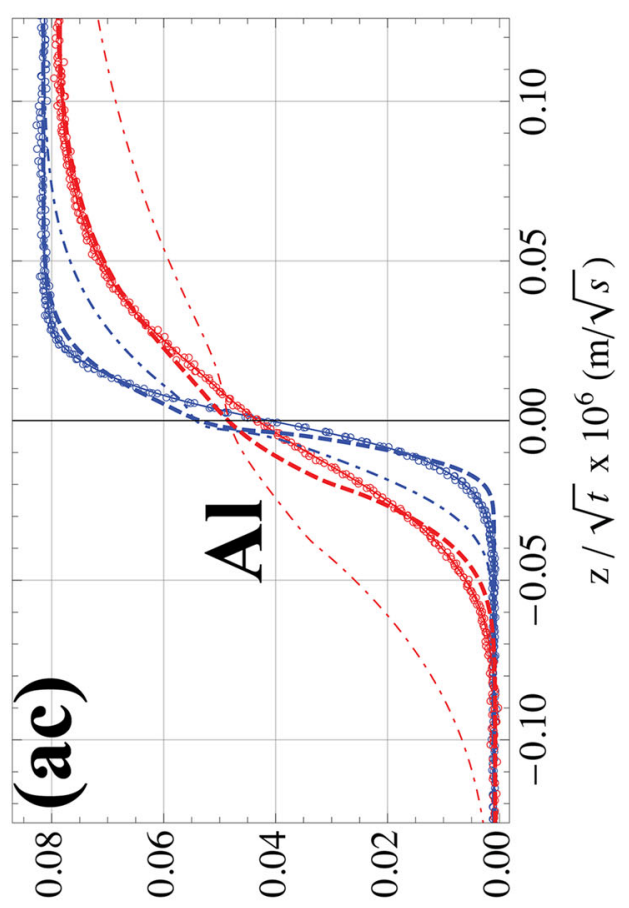

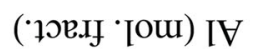

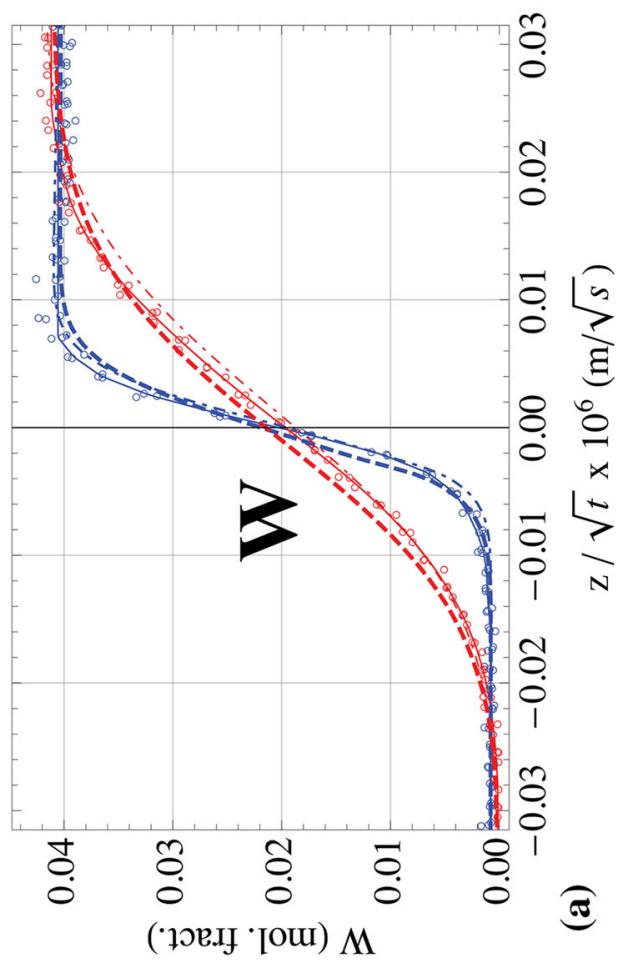

幽它

氞

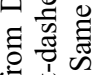

의

氜

记

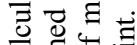

정 $\leftrightarrows 4$.

के के

䒕 要

帘

这.

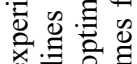

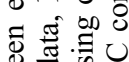

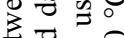

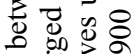

ธี छั

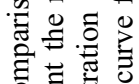

एँ

(త)

$\infty$ s

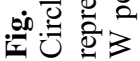




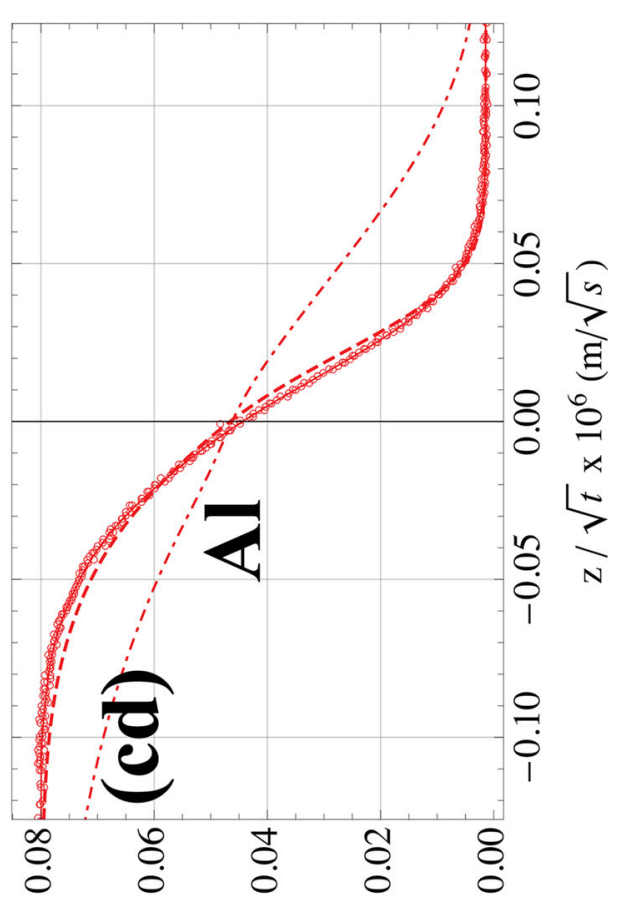

('^ox.If · [OW) IV

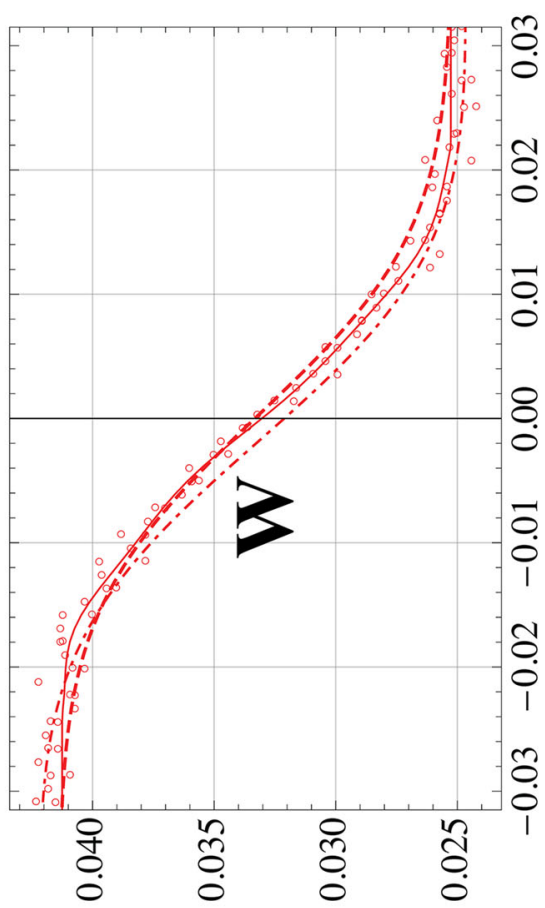

('วอв.Iy · [OW) $M$
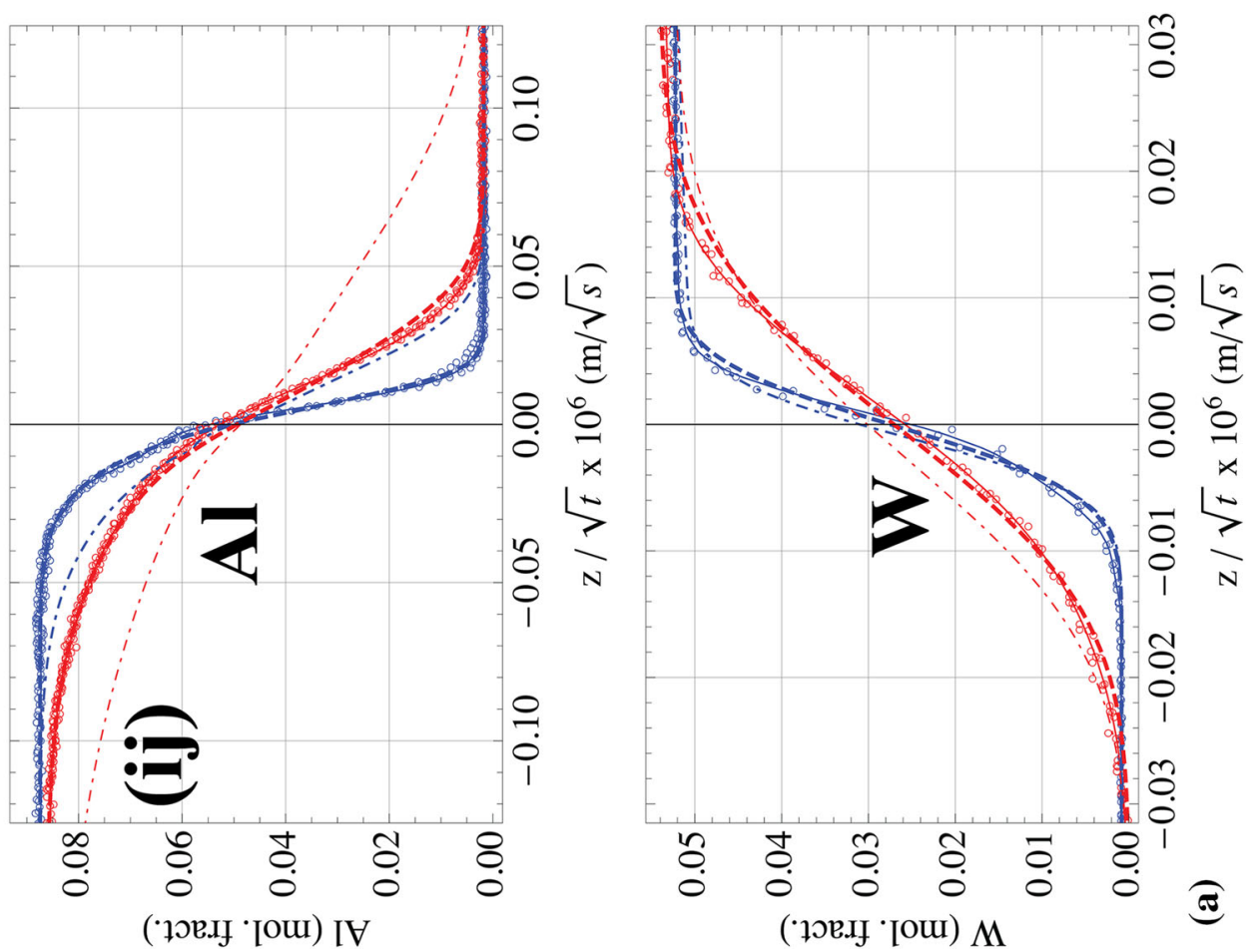

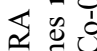

它

O

हี ซี

흥

क्षे

马

효

표의

के क्षे

悉艺

政

気

证

정ㅋㅇ

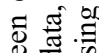

居

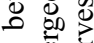

ธ。

흔. 옹

항 


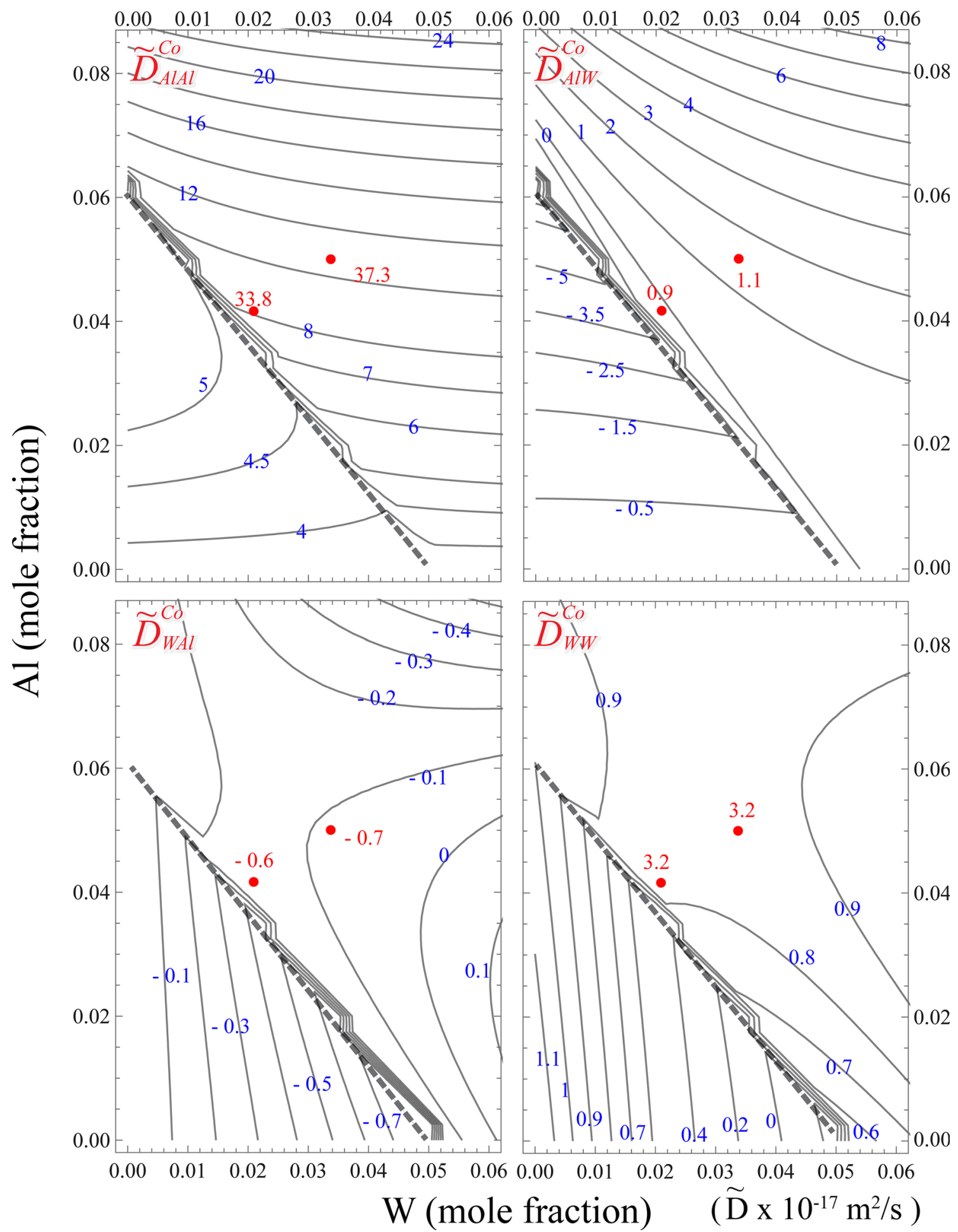

Fig. 10 Diffusivity contour maps for $900{ }^{\circ} \mathrm{C}$ of FCC-gamma phase region using interdiffusion coefficients from DICTRA-Poly 3. Red dots are interdiffusion coefficients calculated by Sauer-Freise method, and values are interdiffusion coefficients listed in Table 4

the correct signs at $900{ }^{\circ} \mathrm{C}$, but the signs are uncertain for several terms at $1000{ }^{\circ} \mathrm{C}$.

Figure 10 and 11 shows contour maps of the four diffusion coefficients at 900 and $1000{ }^{\circ} \mathrm{C}$ calculated with the optimized mobility database. The values obtained from the crossing point procedure are indicated in red. Large variations of the $D$ values with composition are apparent. As is well known, as one approaches the Co-W binary side of the Co-Al-W ternary, the value of $\tilde{D}_{\mathrm{AlW}}^{\mathrm{Co}}$ must vanish, and as one approaches the Co-Al side of the diagram, the value 


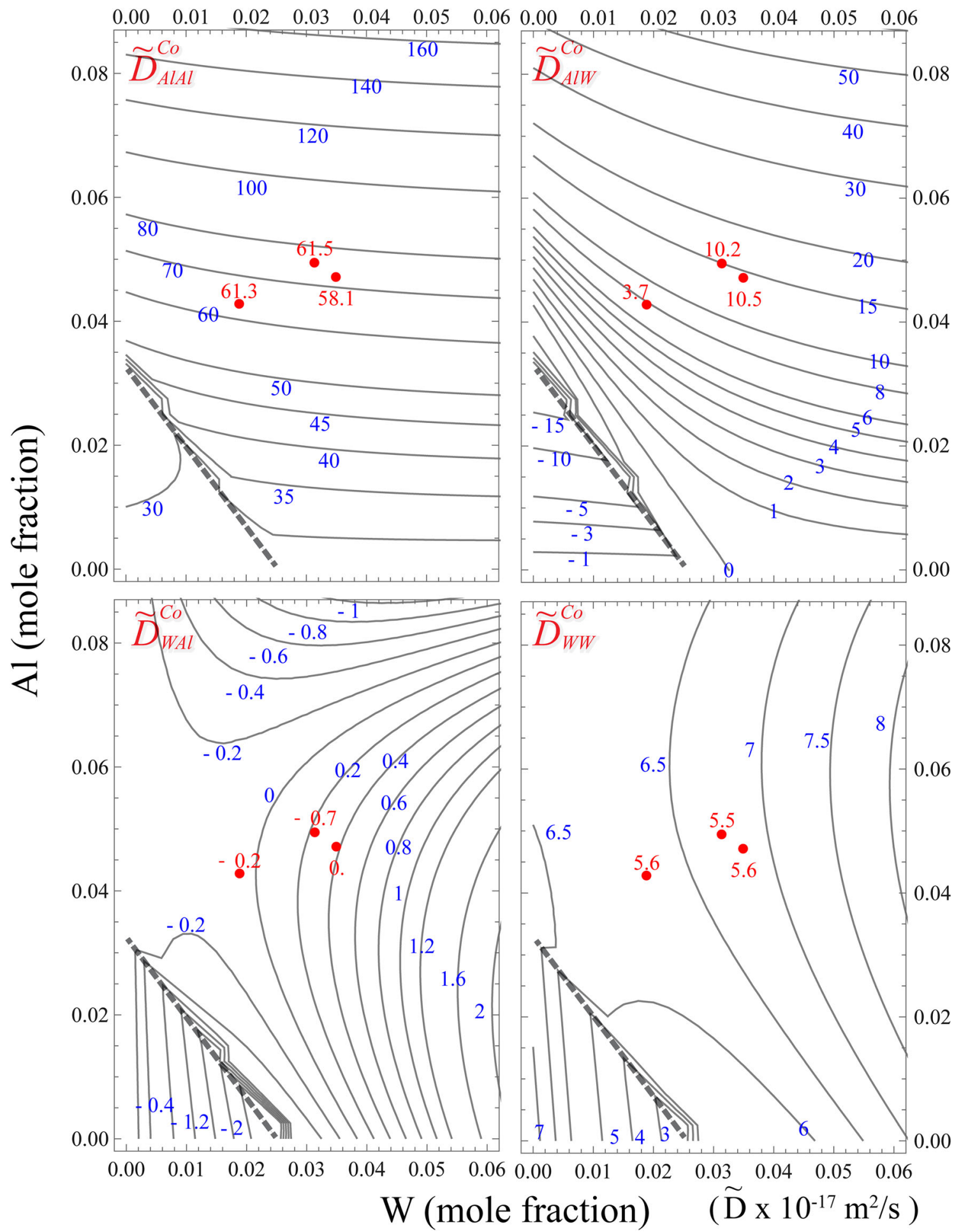

Fig. 11 Diffusivity contour maps for $1000{ }^{\circ} \mathrm{C}$ of FCC-gamma phase region using interdiffusion coefficients from DICTRA-Poly 3. Red dots are interdiffusion coefficients calculated by Sauer-Freise method, and values are interdiffusion coefficients listed in Table 4

of $\tilde{D}_{\text {AlW }}^{\text {Co }}$ must vanish. These properties are evident in the figure. Large changes in values of the $D$ matrix occur at the dashed line in Fig. 10 and 11. For the temperature of the diffusion experiments, the dashed lines indicate the composition boundary between ferromagnetic FCC phase and paramagnetic FCC phase obtained from the thermodynamic assessment.

The uncertainty of the experimentally determined sign of $\tilde{D}_{\mathrm{AlW}}^{\mathrm{Co}}$ is reflected in the fact that the calculated value switches sign with small changes in the composition (ac-ij 
to cd-ij intersections) as seen in the contour map of $\tilde{D}_{\mathrm{AlW}}^{\mathrm{Co}}$ in Fig. 10 and 11. The predicted $\tilde{D}_{\mathrm{AlW}}^{\mathrm{Co}}$ at the crossover compositions are close to zero, and the zero value contour lines are shifted depending on the temperature.

\section{Conclusion}

Diffusion couple experiments between various face centered cubic alloys in the Co-W-Al ternary system have been conducted at 900 and $1000{ }^{\circ} \mathrm{C}$. Diffusion coefficients have been extracted for the Co-W binary and for the ternary alloys at compositions where the diffusion paths cross. In addition, a least squares method has been utilized to optimize diffusion mobility parameters for DICTRA simulations to best fit the experimental concentration versus distance curves. Predictions of the diffusion coefficient matrix using the refined mobility database compare with the values obtained at the diffusion path crossing points as follows. The diagonal terms of the diffusion matrix agree within $80 \%$ at $900{ }^{\circ} \mathrm{C}$ and $25 \%$ at $1000{ }^{\circ} \mathrm{C}$. The offdiagonal terms have the correct signs at $900{ }^{\circ} \mathrm{C}$, but signs are uncertain for several at $1000{ }^{\circ} \mathrm{C}$.

\section{Acknowledgment}

William J. Boettinger acknowledges support from the U.S. Department of Commerce, National Institute of Standards and Technology, under financial assistance award 70NANB15H279.

\section{References}

1. J. Sato, T. Omori, K. Oikawa, I. Ohnuma, R. Kainuma, and K. Ishida, Cobalt-Base High-Temperature Alloys, Science, 2006, 312, p 90-91

2. T. Pollock, J. Dibbern, M. Tsunekane, J. Zhu, and A. Suzuki, New Co-Based $\gamma-\gamma^{\prime}$ High-Temperature Alloys, JOM, 2010, 62, p 58-63

3. F. Xue, H.J. Zhou, X.F. Ding, M.L. Wang, and Q. Feng, Improved High Temperature $\gamma^{\prime}$ Stability of Co-Al-W-Base Alloys Containing Ti and Ta, Mater. Lett., 2013, 112, p 215218

4. M.S. Titus, A. Suzuki, and T.M. Pollock, Creep and Directional Coarsening in Single Crystals of New $\gamma-\gamma^{\prime}$ Cobalt-Base Alloys, Scr. Mater., 2012, 66, p 574-577

5. S.K. Makineni, B. Nithin, and K. Chattopadhyay, A New Tungsten-Free $\gamma-\gamma^{\prime}$ Co-Al-Mo-Nb-Based Superalloy, Scr. Mater., 2015, 98, p 36-39

6. E.A. Lass, M.E. Williams, C.E. Campbell, K.W. Moon, and U.R. Kattner, $\gamma^{\prime}$ Phase Stability and Phase Equilibrium in Ternary Co-Al-W at 900 A degrees C, J. Phase Equilib. Diffus., 2014, 35, p 711-723

7. J. Zhu, M.S. Titus, and T.M. Pollock, Experimental Investigation and Thermodynamic Modeling of the Co-Rich Region in the Co-Al-Ni-W Quaternary System, J. Phase Equilib. Diffus., 2014, 35, p 595-611

8. Y.F. Cui, X. Zhang, G.L. Xu, W.J. Zhu, H.S. Liu, and Z.P. Jin, Thermodynamic Assessment of Co-Al-W System and Solid- ification of Co-Enriched Ternary Alloys, J. Mater. Sci., 2011, 46, $\mathrm{p}$ 2611-2621

9. H. Chang, G. Xu, X.-G. Lu, L. Zhou, K. Ishida, and Y. Cui, Experimental and Phenomenological Investigations of Diffusion in Co-Al-W alloys, Scr. Mater., 2015, 106, p 13-16

10. S. Kobayashi, Y. Tsukamoto, T. Takasugi, H. Chinen, T. Omori, K. Ishida, and S. Zaefferer, Determination of phase equilibria in the Co-rich Co-Al-W ternary system with a diffusion-couple technique, Intermetallics, 2009, 17, p 10851089

11. Y. Tsukamoto, S. Kobayashi, and T. Takasugi, The Stability of $\gamma^{\prime}-\mathrm{Co}(3)(\mathrm{Al}, \mathrm{W})$ Phase in Co-Al-W Ternary System, Pricm 7 , Pts 1-3, J.F. Nie and A. Morton, Ed., Trans Tech Publications Ltd, Stafa-Zurich, 2010, p 448-451

12. N.L. Peterson and S.J. Rothman, Impurity Diffusion in Aluminum, Phys. Rev. B, 1970, 1, p 3264-3273

13. M.S. Anand and R.P. Agarwala, Diffusion of Cobalt in Aluminum, Philos. Mag., 1972, 26, p 297-309

14. R.V. Patil and G.P. Tiwari, Diffusion of Cobalt in Aluminium, Trans. Indian Inst. Met., 1974, 27, p 215-220

15. A. Green and N. Swindells, Measurement of Interdiffusion Coefficients in Co-Al and Ni-Al Systems Between 1000 and $1200{ }^{\circ} \mathrm{C}$, Mater. Sci. Technol., 1000, 1(1985), p 101-103

16. Y. Minamino, Y. Koizumi, N. Tsuji, T. Yamada, and T. Takahashi, Interdiffusion in Co Solid Solutions of Co-Al-CrNi System at 1423 K, Mater. Trans., 2003, 44, p 63-71

17. Y.W. Cui, B. Tang, R. Kato, R. Kainuma, and K. Ishida, Interdiffusion and Atomic Mobility for Face-Centered-Cubic Co-Al Alloys, Mater. Trans. A., 2011, 42A, p 2542-2546

18. J. Ågren, Numerical Treatment of Diffusional Reactions in Multicomponent Alloys, J. Phys. Chem. Solids, 1982, 43, p 385-391

19. J. Ågren, Diffusion in Phases with Several Components and Sublattices, J. Phys. Chem. Solids, 1982, 43, p 421-430

20. J.-O. Andersson and J. Ågren, Models for Numerical Treatment of Multicomponent Diffusion in Simple Phases, J. Appl. Phys., 1992, 72, p 1350-1355

21. W.B. Zhang, D.D. Liu, L.J. Zhang, Y. Du, and B.Y. Huang, Experimental Investigation and Computational Study of Atomic Mobility in FCC Ternary Co-Cr-W Alloys, Calphad Comput. Coupling Phase Diagr. Thermochem., 2014, 45, p 118-126

22. Y.W. Cui, G. Xu, R. Kato, X.-G. Lu, R. Kainuma, and K. Ishida, Interdiffusion and Atomic Mobility for FCC-Centered Cubic (FCC) Co-W Alloys, Metall. Mater. Trans., 2013, 44A, p 5

23. S. Obata, M. Moniruzzaman, and Y. Murata, Interdiffusion in Co-Based Co-Al-W Ternary Alloys at Elevated Temperatures, ISIJ Int., 2014, 54, p 2129-2133

24. T. Gømez-Acedbo, B. Navarcorena, and F. Castro, Interdiffusion in Multiphase, Al-Co-Cr-Ni-Ti Diffusion Couples, $J$. Phase Equilib. Diffus., 2004, 25, p 237-251

25. C.E. Campbell, W.J. Boetttinger, and U.R. Kattner, Development of a Diffusion Mobility Database for Ni-Base Superalloys, Acta Mater., 2002, 50, p 775-792

26. C.E. Campbell, J.C. Zhao, and M.F. Henry, Comparison of Experimental and Simulated Multicomponent Ni-Base Superalloy Diffusion Couples, J. Phase Equilib. Diffus., 2004, 25, p 6-15

27. U.R. Kattner, Construction of a Thermodynamic Database for Ni-base Superalloys: A Case Study, CALPHAD and Alloy Thermodynamics, P.E.A. Turchi, A. Gonis, and R.D. Shull, Ed., TMS, Warrendale, PA, 2002, p 147-164

28. I. Ansara, A.T. Dinsdale, and M.H. Rand, COST 507, Thermochemical Database for Light Metal Alloys, Ver. 2, 
Office for Official Publications of the European Communities, Luxembourg, 1998, p 103-108

29. Y. Peng, Y. Du, P. Zhou, W. Zhang, W. Chen, L. Chen, S. Wang, G. Wen, and W. Xie, CSUTDCC1-A Thermodynamic Database for Multicomponent Cemented Carbides, Int. J. Refract. Met. Hard Mater, 2014, 42, p 57-70

30. Y.W. Cui, K. Oikawa, R. Kainuma, and K. Ishida, Study of Diffusion Mobility of Al-Zn Solid Solution, J. Phase Equilib. Diffus., 2006, 27, p 333-342

31. A. Engström and J. Ågren, Assessment of Diffusional Mobilities in Face-ceneterd Cubic Ni-Cr-Al Alloys, Z. Metall., 1996, 87, p 92-97

32. Y.W. Cui, M. Jiang, I. Ohnuma, K. Oikawa, R. Kainuma, and K. Ishida, Computational Study of Atomic Mobility for FCC Phase of Co-Fe and Co-Ni Binaries, J. Phase Equilib. Diffus., 2008, 29, p 2-10

33. L. Zhang, Y. Du, Y. Ouyang, H. Xu, X.G. Lu, Y. Liu, Y. Kong, and J. Wang, Atomic Mobilities, Diffusivities and Simulation of Diffusion Growth in the Co-Si System, Acta Mater., 2008, 56, p 3940-3950

34. N. Dupin and B. Sundman, A Thermodynamic Database for Ni-Base Superalloys, Scand. J. Metall., 2001, 30, p $184-$ 192
35. N. Dupin and I. Ansara, Thermodynamic Assessment of the System Al-Co, Rev. Metall., 1998, 95, p 1121-1129

36. J. Sato, K. Oikawa, R. Kainuma, and K. Ishida, Experimental Verification of Magnetically Induced Phase Separation in $\alpha \mathrm{Co}$ Phase and Thermodynamic Calculations of Phase Equilibria in the Co-W System, Mater. Trans., 2005, 46, p 1199-1207

37. E. Lass, Molar Volume Assessment, Unpublished Research, NIST, Gaithersburg, MD, 2015, p 20899

38. J.E. Morral, Chemical Diffusivities and their Hidden Concentration Units, J. Phase Equilib. Diffus., 2014, 35, p 581

39. B. Jonsson, Assessment of the Mobilities of $\mathrm{Cr}, \mathrm{Fe}$ and $\mathrm{Ni}$ in bcc Cr-Fe-Ni Alloys, ISIJ International, 1995, 35, p 14151421

40. O. Redlich and A. Kister, Algebraic Representation of Thermodynamic Properties and the Classification of Solutions, Ind. Eng. Chem., 1948, 40, p 345-348

41. B. Jönsson, Assessment of the Mobilities of $\mathrm{Cr}, \mathrm{Fe}$, and $\mathrm{Ni}$ in FCC Cr-Fe-Ni Alloys, Z. Metallkunde, 1995, 86, p 686-692

42. DICTRA, Thermo-Calc AB, DICTRA, Stockholm, Sweden, 2003

43. N. Saunders, Phase Diagram Calculations for Ni-Based Superalloys, Superalloys 1996, R.D. Kissinger, Ed., TMS, Warrendale, PA, 1996, p 101-110 